\title{
Twin reversed arterial perfusion in one foetus in a triplet pregnancy with a singleton foetus and dichorionic monoamniotic twins conceived with in vitro fertilization: A case report
}

\section{Linda R Chambliss*}

Professor of Obstetrics and Gynecology, Creighton University School of Medicine, Clinic Professor of Obstetrics and Gynecology, University of Arizona College of Medicine, Arizona

\section{Case report}

A 36-year-old G3P1011 presented at 9 3/7 weeks of gestation by embryo transfer dating for her initial ultrasound. She had had 5 prior uncomplicated term normal spontaneous vaginal deliveries but had had a prior bilateral tubal ligation and now had a new partner. She did not want to undergo an attempt at tubal re-anastomosis. She did not have pre-implantation genetic diagnosis. We did not have any records as to how many embryos were transferred. The remainder of her health history was significant for a diagnosis of latent tuberculosis 14 years ago without any current symptoms and possible chronic hypertension. However, she was not taking any antihypertensives and was normotensive on exam.

The ultrasound showed a triplet pregnancy with a singleton dichorionic diamniotic foetus and a dichorionic monoamniotic twin gestation with two of the three triplets with crown rump lengths consistent with her egg transfer dating. The twins were dichorionic with respect to the singleton but dichorionic-monoamniotic with respect to each other (Figure 1). Cardiac activity was clearly seen in the singleton triplet $\mathrm{C}$ as well as triplet $\mathrm{A}$. Triplet $\mathrm{B}$ had a single umbilical artery and no cardiac activity could be demonstrated with real time ultrasound, pulsed wave doppler or color flow doppler on triplet B. There was rudimentary development of the head. However, there was clearly blood flow in Triplet B documented with color flow doppler (Figure 2). A diagnosis of an acardiac triplet due to twin reversed arterial perfusion was made. The patient was counseled on the maternal and foetal complications associated with higher order multiples, advanced maternal age, the use of artificial reproduction and an acardiac foetus. She was advised of the options for prenatal diagnosis and offered a genetic amniocentesis to be performed at 16 weeks gestation. She declined any genetic testing. The patient was further counseled that triplet $\mathrm{B}$ had, unfortunately, a lethal diagnosis.

The patient had ultrasounds every 4 weeks for interval growth and every 2 weeks to evaluate triplet A twin for signs of foetal anemia and/ or hydrops. Table 1 is a summary of the ultrasound examinations. The acardiac triplet did not demonstrate any blood flow on the ultrasound performed at 18 weeks.

The patient presented at $251 / 7$ weeks with contractions and bleeding. Triplet A was a footling breech. An ultrasound was performed and the estimated fetal weight triplet A was 843 grams while triplet
C had an estimated fetal weight of 837 grams. The neonatal intensive care physician counseled the patient as to the expected outcome for an estimated gestational age of $251 / 7$ weeks. The patient was given betamethasone for foetal lung maturity and started on magnesium sulfate for neuroprotection. However, she did not complete the full course of antenatal steroids as her bleeding increased significantly. A decision was made to proceed with delivery and she underwent a classical cesarean section. Triplet A weighed 890 grams with Apgars of $8 / 6 / 9$ and umbilical cord gases which showed venous $\mathrm{pH} 7.30 \mathrm{pO}_{2}<28$, $\mathrm{pCO}_{2} 52$ and arterial $\mathrm{pH} 7.30 \mathrm{pO}_{2}<28$ and $\mathrm{pCO}_{2} 38$. Triplet $\mathrm{C}$ weighed 840 grams with Apgars of 7/4/9 and umbilical vein results of $\mathrm{pH} 7.27$

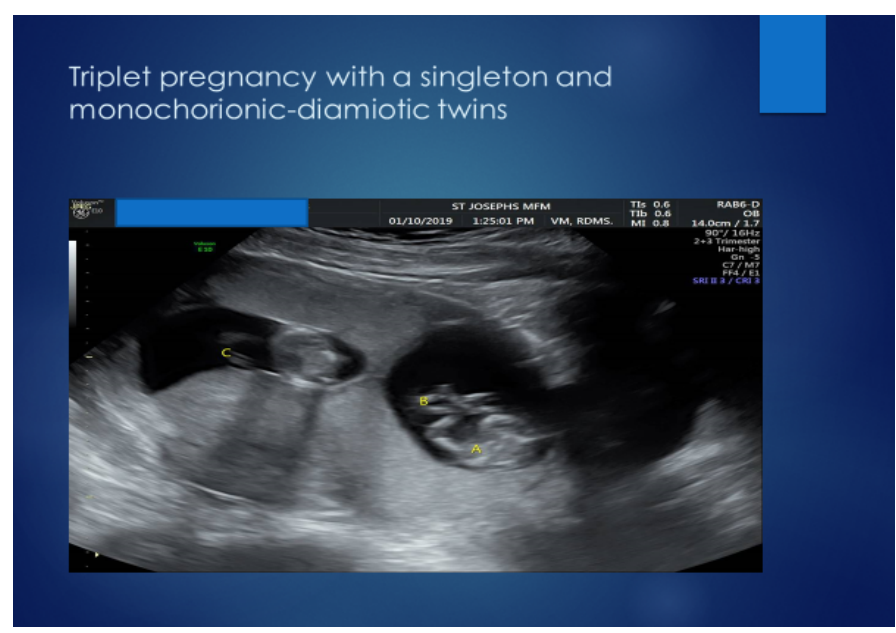

Figure 1. Triplet pregnancy with dichorionic monoamniotic twins and a singleton dichorionic with respect to the twins

*Correspondence to: Linda $\mathrm{R}$ Chambliss, Professor of Obstetrics and Gynecology, Creighton University School of Medicine, Clinic Professor of Obstetrics and Gynecology, University of Arizona College of Medicine, Arizona, E-mail: 1rchambliss@yahoo.com

Key words: assisted reproductive techniques, acardiac foetus, cardiac dysmorphogenesis

Received: January 26, 2020; Accepted: February 07, 2020; Published: February 11,2020 


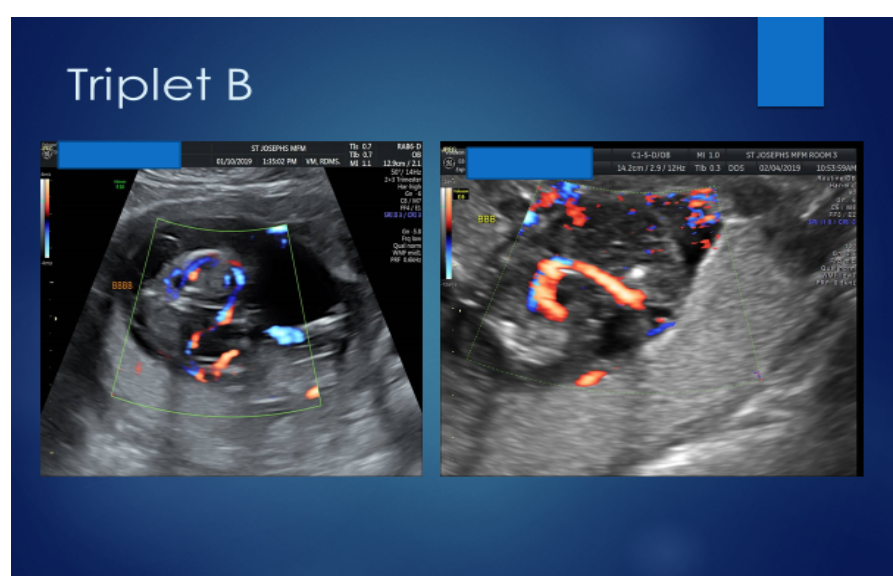

Figure 2. Blood flow in amorphous appearing triplet C

Table 1. Results of ultrasounds

\begin{tabular}{|c|c|}
\hline Estimated gestational age & Findings \\
\hline 9 weeks 3 days & $\begin{array}{l}\text { Triplet pregnancy with a single foetus and dichorionic } \\
\text { monoamniotic twins. Crown rump lengths: triplet A } 24.9 \mathrm{~mm} \text {; } \\
\text { triplet B19.6 mm; triplet C: } 25.6 \mathrm{~mm} \\
\text { EGA of triplet A and C were concordant with ART dating } \\
\text { and both demonstrated cardiac activity. Triplet B did not have } \\
\text { cardiac activity but had blood flow to the triplet }\end{array}$ \\
\hline 12 weeks 5 days & $\begin{array}{l}\text { Nuchal translucency of twin A was } 1.8 \text { with a nasal bone present } \\
\text { No Nuchal translucency could be determined for Triplets B or C }\end{array}$ \\
\hline 14 weeks 5 days & $\begin{array}{l}\text { Continued blood flow noted in triplet B } \\
\text { No signs of hydrops in triplet A }\end{array}$ \\
\hline 16 weeks 2 days & $\begin{array}{l}\text { Continued blood flow in triplet B who was now hydropic } \\
\text { No hydrops noted in either triplet A or C }\end{array}$ \\
\hline 18 weeks 2 days & $\begin{array}{l}\text { No blood flow noted in triplet B } \\
\text { No hydrops in triplet A and no evidence of foetal anemia by } \\
\text { peak systolic velocity in the middle cerebral artery of triplet A }\end{array}$ \\
\hline 19 weeks 2 days & $\begin{array}{l}\text { No hydrops in triplet A and no evidence of foetal anemia by } \\
\text { peak systolic velocity in the middle cerebral artery of triplet A } \\
\text { Normal detailed anatomical scans of both triplet A and triplet C }\end{array}$ \\
\hline 20 weeks 2 days & $\begin{array}{l}\text { No hydrops in triplet A and no evidence of foetal anemia by } \\
\text { peak systolic velocity in the middle cerebral artery of triplet A }\end{array}$ \\
\hline 22 weeks 2 days & $\begin{array}{l}\text { No hydrops in triplet A and no evidence of foetal anemia by } \\
\text { peak systolic velocity in the middle cerebral artery of triplet A }\end{array}$ \\
\hline 23 weeks 2 days & $\begin{array}{l}\text { No hydrops in triplet A and no evidence of foetal anemia by } \\
\text { peak systolic velocity in the middle cerebral artery of triplet A }\end{array}$ \\
\hline 25 weeks 2 days & $\begin{array}{l}\text { Triplet A footling breech with EFW of } 843 \text { grams } \\
\text { Triplet C with EFW of } 837 \text { grams }\end{array}$ \\
\hline
\end{tabular}

$\mathrm{pO}_{2}<28$ and $\mathrm{pCO}_{2}$ 58. A sample from the umbilical artery of triplet $\mathrm{C}$ could not be obtained.

The surviving triplets were transferred to the neonatal intensive care unit. Neither triplet had any intracranial bleeding. Triplet $C$ was discharged at 99 days of age (39 weeks gestation) on room air while triplet A was discharged at 135 days of age (43 weeks of gestation) on supplemental oxygen.

The patient had multiple risks factors for a congenital malformation: advanced maternal age, the use of ART, higher order multiples and a single umbilical artery in triplet B. Advanced maternal age is linked to a higher risk of aneuploidy [1,2]. There is conflicting evidence if advanced maternal age increases the risk of malformations. Some studies have suggested that malformations are not increased [2,3]. Other authors report advanced maternal age is a risk factor [4,5]. Other studies have suggested that the risk begins to rise after age 20 due to an increased risk of trisomy 18 which commonly presents with multiple anomalies on ultrasound. Trisomy 18 results from an error in meiosis II and the increase in risk occurs as early as 20 years of age [5]. Other data have shown the increased risk begins after age 40. The National Birth Defects Prevention study showed that maternal age over 40 increased the risk of cardiac defects, hypospadias, craniosynostosis and esophageal atresia [1].

\section{Discussion}

The use of assisted reproductive techniques (ART) is associated with an increase in both maternal and fetal complications [6-8]. Spontaneous abortion is more common with ART as are congenital malformations [9]. Many, but not all, of the complications are due to the higher rate of multiple gestations. Several reviews have shown an association between the use of ART and an increased rate of intrauterine fetal demise and ART increases the risk of low birth weight, small for gestation age and preterm birth $[6,8]$. The rate of preterm birth is basically identical in triplet ART conceived pregnancies compared to spontaneous conceptions, $97.7 \%$ and $97 \%$ respectively, but the rates of preterm birth are higher for both twins and singletons conceived with ART. In ART $13.7 \%$ of singletons and $64.2 \%$ of twins are preterm compared with an overall rate of $7.8 \%$ in singletons and $59.9 \%$ in spontaneously conceived twins [6]. The maternal complications include an increased risk of hypertensive disorders in pregnancy and placenta previa $[4,7]$. Other maternal risks are antepartum hemorrhage, abruption, cesarean delivery [7]. Antenatal admission rates are higher for women whose pregnancies were conceived with ART [10]. Although the overall rates are decreasing, severe maternal morbidity rates are higher in women with singleton gestations conceived with ART compared to those that are spontaneous conceptions primarily due to an increase need for transfusion, an increase in disseminated intravascular coagulation and more need for mechanical ventilation [11].

Although a single umbilical artery (SUA) can be seen in as many as $1 \%$ of normal fetuses, it is very common in both trisomy 18 and trisomy 13 [12]. It has been reported in as many as $5 \%$ of twin pregnancies [5]. A SUA increases the risk of a number of adverse pregnancy outcomes including congenital anomalies, aneuploidy, prematurity and intrauterine growth restriction [13]. There is a 4-fold increase in the risk of perinatal mortality and that as many as one third of pregnancies with a SUA will also have a congenital anomaly, most commonly cardiac [14].

Twin reversed arterial perfusion (TRAP sequence) is a rare, severe known complication of a monoamniotic twin pregnancy which occurs in $1 \%$ of monochorionic twins or about $1 / 30,000$ pregnancies [15]. It has been reported in both monochorionic diamniotic twins as well as monochorionic monoamniotic twins and higher order multiples but never in a singleton gestation. It has been described since the $16^{\text {th }}$ century. Schatz and Klinische first reported the abnormal placenta circulation in TRAP sequence in 1900 when they described arterialarterial and venous-venous vascular connections [16]. The exact pathogenesis of arcadia twin in unknown but several theories have been advanced to explain this phenomenon. There is general agreement that certain circumstances are present. One of the twins in a usually monochorionic pregnancy must have either a non- functioning heart or circulatory failure very early in the pregnancy, probably between 8 and 12 weeks. This could be due to fertilization of a polar body, disrupted development of a normal heart by some insult or a primary cardiac defect. Furthermore, the placenta must have at least one direct arterial-arterial anastomosis between the twins and often has venousvenous connections as well. It is controversial to what is the primary event and what is a secondary consequence: abnormal placental blood 
flow leading to an abnormal or even absent heart or an abnormal heart that results in abnormal blood flow in the placenta [5]. Coulam and Wright reported on a patient with a monochorionic gestational sac with 2 embryos demonstrating cardiac activity at 5 weeks. One twin lost cardiac activity at 7 weeks. Subsequently, an ultrasound at 14 weeks showed reversed blood flow through the umbilical cord of the twin with no heart beat confirming the earlier impression of an acardiac twin. They concluded that the primary mechanism is "cardiac dysmorphogenesis secondary to the reversal of blood flow rather than primary cardiac agenesis based on their findings in the first trimester [16]. The acardiac twin receives blood from its co-twin, not from the placenta so the blood is less well oxygenated. The blood is also preferentially directed towards the towards the lower half of the acardiac fetus which accounts for the more normally appearing lower abdomen and legs. The upper abdomen, chest and head are less well developed and may not even be present at all.

TRAP sequence is also defined by the degree of development of the fetus. If there is failed head growth it is termed acardius acephalus. If there is a malformed head and extremities it is referred to as acardius myelacephalus [4]. A twin with a rudimentary heart or cardiac structed is called hemiacardius while a twin with an absent heart is referred to as holoacardius [17]. An acardiac twin in which there are no identifiable organs is term acardius amorphous.

TRAP has been reported to be diagnosed in the first trimester using color flow doppler to document that umbilical vein blood flow in the acardiac twin goes from the twin to the placenta instead of the normal circulation which is from the placenta to the fetus. Langlotz reported her group was able to confirm this diagnosis in a twin gestation at 12 weeks gestation using transvaginal Doppler sonography to demonstrate the absence of cardiac activity in one twin who was also anencephalic with a cystic mass noted posterior extending up to the neck [18]. Another method to diagnosis TRAP is to use color flow doppler to show the direction of blood flow in the umbilical vein of the acardiac twin is reversed as described by Papa and colleagues. They were able to show that a normal fetus has blood flowing from the placenta to the fetus through the umbilical vein as expected while the acardiac twin's umbilical vein blood flow is from the fetus to the placenta [19].

The acardiac twin is, of course, non-viable and over 50\% have chromosomal anomalies [12,14]. Frequently there is a single umbilical artery. Other ultrasound findings include cystic hygroma and polyhydramnios $[12,14]$. The prognosis for the normal, so called "pump twin", varies depending upon its own karyotype, the presence of other malformations, the size of the acardiac twin and the doppler flow studies of the umbilical al arteries. Moore, et al. reported if the volume of the acardiac twin were more than $70 \%$ of the pump twin, the prognosis was poor. If the volume were less than $50 \%$, the prognosis for survival of the pump twin improved. The volume of the acardiac twin was measured by using the following formula: length $\mathrm{X}$ width $\mathrm{X}$ height $\mathrm{X} \pi / 6$ [20]. Dashe reported that the prognosis could be defined by the difference in the resistance indices of the umbilical arteries in each umbilical cord. In pregnancies where there was at least a 0.20 difference in the resistance index suggesting lower flow to the acardiac twin, the prognosis for the pump twin improved. If the difference in the resistance indices were lower than $<0.05$, implying a larger flow to the acardiac twin, the prognosis for the pump twin was poor [21].

Several options have been proposed to treat TRAP and improve the survival of the pump twin. In less severe cases, it is reasonable to expectantly manage the twins while continuing to monitor growth and perform antepartum fetal testing. In more severe cases, there are a number of approaches that have been used: foetoscopic laser coagulation of the placental vascular anastomoses sometimes accompanied by bipolar cord occlusion as well, selective foetocide of the acardiac twin, foetoscopic cord occlusion using bipolar cord coagulation and most recently radiofrequency ablation of the abdominal cord insertion site of the acardiac twin. Cases that are appropriate for intervention include those where a twin has hydropic changes, there is an elevated perfused twin to pump twin ratio or high combined ventricular output in the pump twin [22]. The advantages of foetoscopic laser coagulation of the placental vascular anastomoses is there is an increasing larger experience with using laser photocoagulation but the disadvantage is that the anastomoses sites may be relatively in accessible depending upon the location of the placenta and the procedure alone may not be completely successful in reversing the shared circulation. The advantages of bipolar coagulation are it is a relatively brief procedure and may reduce the risk of septum disruption which lessens the risk of future cord entanglement. The disadvantage of bipolar coagulation is it may not be successful with a larger cord diameter [23]. Radiofrequency ablation (RFA) is becoming the more commonly used technique. In RFA a small needle is inserted percutaneously through the maternal abdomen to reach the abdominal wall insertion site of the umbilical cord of the acardiac twin. An electrical current is then passed until there is no blood flow in the cord as determined by doppler flow ultrasound. The advantage is the needle is smaller than the fetoscope that is used with other approaches [22]. The disadvantage is this has been reported to result in amniotic bands, fibrous bands or a loop of cord that entangles the normal umbilical cord resulting in the compromise or loss of the normal twin [24]. Other concerns are causing premature rupture of membranes or technical difficulty in establishing complete cessation of blood flow to the acardiac twin. It is generally helpful to evaluate the blood flow in the cord in several places both before and after the procedure [25].

A PubMed search of triplet pregnancies complicated by an acardiac triplet yielded several other case reports as well as multiple reports of an acardiac foetus in twins. This patient was perhaps one of earliest diagnosis of an acardiac foetus in a triplet pregnancy. Al-Malt, et al. recounted diagnosing a triplet with an acardiac foetus at 20 weeks [26]. In the report by Yiidirim of a triplet pregnancy complicated by an acardiac triplet, the ultrasound was performed at 31 weeks [27]. Kamitomo described discordant twins with a cystic mass noted in the smaller twin at 11 weeks but the diagnosis of acardia was not confirmed until 15 weeks of gestation [28].

\section{Conclusion}

This case illustrates that it is possible to make a first trimester diagnosis of TRAP even in higher order multiples. This offers the patients the widest range of options regarding pregnancy termination and genetic testing. It also gives the opportunity to allow for consultation and possible transfer to a fetal care center for treatment options before the pump twin becomes severely affected. Although TRAP sequence is a rare complication of dichorionic monoamniotic or monochorionic monoamniotic twins and even rarer in higher order multiples, it does occur and clinicians need to be aware of the diagnosis and treatment approaches.

\section{References}

1. Harris BS, Bishop KC, Kemeny HR, Walker JS, Rhee E, et al. (2017) Risk factors for birth defects. Obstet Gynecol Surv 72: 123-135.

2. Fredersiksen L, Ernst A, Brix N, Braskhøj Lauridsen LL, Roos L, et al. (2018) Risk of adverse pregnancy outcomes at advanced maternal age. Obstet Gynecol 131: 457-463 
Chambliss LR (2020) Twin reversed arterial perfusion in one foetus in a triplet pregnancy with a singleton foetus and dichorionic monoamniotic twins conceived with in vitro fertilization: A case report

3. Best KE, Rankin J (2016) Is advanced maternal age a risk factor for congenital heart disease? Birth Defects Res A clin Mol Teratol 106: 461-467.

4. Cunningham FG, Leveno K, Bloom S, et al. (Eds.) (2018) Chapter 14: Prenatal diagnosis in Williams obstetrics, $25^{\text {th }}$ Edition, New York: McGraw-Hill.

5. Resnick R, Lockwood C, Moore T, et al. (Eds) (2018) Chapter 32: Prenatal diagnosis in maternal-fetal medicine $8^{\text {th }}$ Edition Elsevier: Philadelphia.

6. CDC: Assisted reproductive technology surveillance-United States, 2016. Morbidity and Mortality Weekly report April 26, 2019.

7. Kawass JF, Badell ML (2018) Maternal and fetal risks associated with assisted reproductive technology. Obstet Gynecol 132: 763-772.

8. Talaulikar V, Arulkumaran S (2012) Reproductive outcomes after assisted conception. Obgyn Survey 67: 566-583.

9. Schieve L, Rasmussen S, Buck G, Schendel DE, Reynolds MA, et al. (2004) Are children born after assisted reporductive techniques at increased risk for adverse health outcomes? Obstet Gynecol 103: 1154-1163.

10. Martin A, Zhang Y, Crawford S, Boulet SL, McKane P, et al. (2016) Antenatal hospitalizations among pregnancies conceived with and without assisted reproductive technology. Obstet and Gynecol 127: 941-950.

11. Martin A, Monour M Kissin DM, Jamieson DJ, Callaghan WM, et al. (2016) Trends in severe maternal morbidity after assisted reproductive technology in the United States, 2008-12. Obstet Gynecol 127: 59-66.

12. Nyberg D, McGahan J, Pretorius D, Pilu G (Eds.) (2003) The placenta, umbilical cord and membranes in diagnostic imaging of fetal anomalies. Philadelphia: Lippincott. Williams and Wilkins.

13. Murphy-Kaulbeck L, Dodds L, Joseph KS, Van den Hof M (2010) Single umbilical artery risk factors and pregnancy outcome. Obstet Gynecol 116: 843-850

14. Fleischer A, Manning F Jeanty P, Romero R (Eds.) (2001) Sonography in obstetrics and gynecology. $6^{\text {th }}$ edition New York: McGraw-Hill.

15. Oliver E, Coleman B, Goff D, Horii SC, Howell LJ, et al. (2013) Twin reversed arterial perfusion sequence. J Ultrasound Med 32: 2115-2123.
16. Coulam CB, Wright G (2000) First trimester diagnosis of acardiac twins. Early Pregnancy 4: 261-270.

17. Landy H, Larsen J, Schoen M, Larsen ME, Kent SG, et al. (1988) Acardiac foetus in a triplet pregnancy. Teratology 37: 1-6.

18. Langlotz H. Sauerbrei E, Murray S (1991) Transvaginal doppler sonographic diagnosis of an acardiac twin at 12 weeks gestation. J Ultrasound Med 10: 175-179.

19. Papa T, Dao A, Bruner J (1997) Pathognomonic sign of twin reversed arterial perfusion using color doppler sonography. J Ultrasound Med 16: 501-503.

20. Moore T, Gale S, Benirschke K (1990) Perinatal outcome of forty-nine pregnancies complicated by acardiac twinning. Am J Obstet Gynecol 163: 907-912.

21. Dasche J, Fernandez C, Twickler D (2001) Utility of doppler velocimetry in predicting outcome in twin reversed-arterial perfusion sequence. Am J Obstet Gynecol 185: 135-139.

22. Livingston JC, Lim F-Y, Polzin W, Mason J, Crombleholme TM (2007) Intrafetal radiorfrequency ablation for twin reversed arterial perfusion (TRAP): a single center experience. Am J Obstet Gynecol 197: 339-399.

23. Rossi C, D'Addario V (2009) Umbilical cord occlusion for selective feticide in complicated monochorionic twin pregnancies. Am J Obstet and Gynecol 2: 123-129.

24. Tollenaar L, Knijnenburg PCJ, Wolf JL, Slaghekke F, Middeldorp JM, et al. (2019) Fatal umbilical cord strangulation in the remaining co-twin after selective foeticide with radiofrequency ablation for twin-twin transfusion syndrome. Fetal Diag There 45: 441-444.

25. Lee H, Wagner AJ, Sy E, Ball R, Feldstein VA, et al. (2007) Efficacy of radiofrequency ablation for twin-reversed arterial perfusion sequence. Am J Obstet Gynecol 196 $459 \mathrm{e} 1-459 \mathrm{e} 4$.

26. Al-Malt A, Asmead G, Judge N, Mann L, Ashmead J, et al. (1991) Color-flow dopple velocimetry in prenatal diagnosis of acardiac triplet. J Ultrasound in Med 10: 341-345.

27. Yidirim E (2019) Spontaneous triplet pregnancy and trap sequence, case report. BMC Pregnancy and Childbirth 19: 328 .

28. Kamitomo M, Kouno S, Ibuka K, Oku S, Sueyoshi K, et al. (2004) First-trimester findings associated with twin reverse arterial perfusion sequence. Fetal Diagn Ther 19: 187-190.

Copyright: (C2020 Chambliss LR. This is an open-access article distributed under the terms of the Creative Commons Attribution License, which permits unrestricted use, distribution, and reproduction in any medium, provided the original author and source are credited. 